\title{
Research on the Current Situation of Chinese Traditional Martial Arts Chunguang $\operatorname{Pan}^{1, \text { a }}$ \\ ${ }^{1}$ Physical Education Department of Wuchang Institute of Technology, Wuhan, Hubei, China, 430065 \\ ${ }^{a}$ email,
}

Keywords: Traditional Martial Arts, Meaning, Current Situation, Countermeasure

\begin{abstract}
This paper analyses the development of China's traditional martial arts through reading data, summarizes the problems in the development of traditional martial arts and the factors that influence the development of traditional martial arts, while putting forward their views on countermeasures of traditional martial arts inheritance and development. Look ahead traditional martial arts into the world sport and make recommendations on the development direction of traditional martial arts.
\end{abstract}

\section{Introduction}

Martial Arts is a fine Chinese tradition of sports, the development has spawned competitive martial arts, martial arts fitness, military and police martial arts school martial arts, traditional martial arts and all kinds, regardless of what kind of martial art, its roots should be derived from the traditional martial arts. Chinese martial arts have a long history, profound. National Sports Commission in 1979 began to send investigation team to inspect Chinese traditional martial arts then our country has identified 129 self-contained boxing. However, so many boxing currently but there have been many problems: some routines successors; some boxing has been lost; some only finishing the manuscript and nobody exercises; some just retains routine "appearance" It lost its inherent "content"; a traditional martial arts are not well thought heritage; martial arts culture is not well carry forward the like. In order to foothold in the world sports family, there are some problems of Chinese martial arts are awaiting the outcome.

\section{The Development Current Situation of Traditional Martial Arts}

The Popularity and Inheritance of Traditional Martial Arts. With the popularization and improvement of national fitness campaign, the demand for increasingly high fitness. National Martial Arts Administrative Center survey statistics show. China's current spread of martial arts and has been registered civil martial arts schools that have more than 12000 and the number of regular exercise in the martial arts has reached more than 6,500 people. These populations, the elderly Tai Chi, magnolia, Qigong as the main body, teenagers with athletic routines, routines and regulations as the main fighting, children places juvenile boxing regulations as the main pattern; a traditional boxing exercises (mechanical) of the number of man-made not much. In our school sports (large, medium, small, private martial arts schools) teaching, almost all in competitive martial arts as the main body, although the textbooks have been incorporated into a number of elementary routines, but in the actual teaching teachers truly Press Gang implementation rarely, in ordinary schools can be fully qualified teachers teaching martial arts is relatively small, especially for the connotation of martial arts to know more of the poor. Now University of Martial Arts for primary materials are essentially routine, not to mention the traditional teaching of the martial arts, martial arts schools now teaching a single boring, this form of succession is indeed worrying.

The Propagation of Traditional Martial Arts Culture. China's Martial Arts after several generations of inheritance and development has been the formation of a special culture that is martial arts culture. Martial Arts culture is rich in content and it is the fusion of philosophy, traditional Chinese medicine, health, qigong, table tennis, aesthetics, ethics, moral science and other content. However, in today's martial arts spread in the rich connotation of martial arts confused 
culture off my back, even to gathered disciples, to overcharging tuition desperate to receive anyone inside. Martial Arts Culture is neither education nor pay attention to cultivation, which resulted from many martial arts school graduates terrorizing society, or even to a life of crime to social stability and brought some hidden dangers.

\section{The Analysis of Causes}

Incoming Western sports culture is constructed of competitive martial arts reproduction platform, the traditional martial arts has been a great impact. With the development of globalization, the Western Competitive Sport on Chinese traditional martial arts had a huge impact, calls for change soaring. Officially this advocating "military exercise" strong desire to overwhelm the traditional martial arts, western sports "military exercise" has become the official school curriculum, and promote the martial arts reform movement and "new martial arts," the rapid development has accelerated the traditional martial arts of fission, traditional martial arts was shelved. Forming a Competitive Martial Arts and the Traditional antithesis continues to this day and intensified.

Mining martial arts heritage hot start work until finishing cold stranded, leading to sluggish scientific traditional martial arts is a major factor. National Martial Arts Administrative Center in the regulation of traditional martial arts, can be described as the next big effort, which lasted more than three years, employing more than 8,000 people, conducted for the National Traditional Martial Arts finishing mining, excavation, a total of 129 kinds of self-contained boxing, collected 651 million words of boxing, armed recorded. So far most of the information can only be as dusty moth-eaten, shelved, which reflects the decision-making of Traditional inadequate attention. Later development, research is stranded state, which is leading to stagnant traditional martial arts scientific and technological development lag a major factor.

\section{Strategies to Promote the Development of Traditional Martial Arts}

Traditional Chinese martial arts have a rich culture, its variety, action martial stronger. However, the development of today's traditional martial arts is not good, or the tradition of the wrong way, or spread via the incompleteness and the like. Traditional Chinese martial arts in the world, in order to have a foothold, we must first develop a good, good succession, followed by the traditional martial arts to make a comprehensive development, universal.

Based on Domestic and Carry forward the Traditional Martial Arts. We need to re-published textbook of traditional martial arts. After the excavation, the results of the 1986 national exhibition in Beijing published nationwide traditional martial arts books and audiovisual materials are few. Most were published so far Competitive Martial Arts and traditional martial arts is relatively small, and these books are mostly university library subscribes to the vast majority of traditional martial arts bookstore almost no information. In order to let more people understand the traditional martial arts, traditional martial arts should be a large number of published books and audio-visual materials, as a way to promote the development of traditional martial arts.

We should make full use of the educational function of traditional martial arts culture. Chinese martial arts culture is an integral part of Chinese culture as a whole, which is in the historical context of culture and martial arts culture is inevitably formed. This rich culture, which lasted a long, profound, one thousand one hundred vine, it is also fully implement, reflects the basic spirit of Chinese culture. Carry forward the Chinese martial arts carry forward the national culture is the basic spirit of that vigorous and promising, Ambitious in spirit; ethical culture, special emphasis on interpersonal humanistic spirit; Chinese cultural exclusion theological religious system of secularization spirit; "Heaven" respect for the natural spirit; emphasis on kinship, kinship groups patriarchal relations. Martial Arts Culture self-contained represents a component part of Chinese culture, a cultural form unique to China. Thus, while the development of traditional Chinese martial arts we also should develop Chinese culture.

We should make efforts to expand market of traditional martial arts culture. Development of Traditional Martial Arts competition show expanding domestic market, the traditional martial arts 
training market, traditional martial arts tourism market, as well as traditional martial arts commercial market; through the organization of cultural festivals and other forms of martial arts so that more people understand the value of traditional martial arts performances, a fitness value, entertainment value, economic value, and the value of self-defense and so on.

Promote the International Development of Traditional Martial Arts. Competitive Martial Arts After 30 years of effort and development, many countries in the world have joined the International Martial Arts Federation, the world of martial arts competitions conducted quite good, which shows the development of Chinese martial arts is still productive. Among the family of boxing martial arts, tai chi as the representative of a small number of boxing has been out of the country, into the world. On the basis of the traditional martial arts of the emerging competitive martial arts project, also have their own World Championships and the Olympic Games are to strive to enter and work. However, the degree of internationalization of the traditional martial arts is not high. Needless to say, with the Olympics compared to many Western countries, is the rise in the neighborhood of judo, taekwondo compared, there are also a big gap. A step ahead of others, we can learn from the successful experience, unsatisfactory "lesson" is also worth a warning. It should be said, the international development of traditional martial arts started late. However, the election of the method, our traditional martial arts come from behind is still promising.

We need to combine the government communication and non-governmental exchanges. A country can send to the martial arts professionals around the world to teach the traditional martial arts, martial arts together to build a fitness center, martial arts clubs, public education and organizing International Traditional Martial Arts Competition and International Traditional Martial Arts competitions, which can be called the official dissemination. Others, such as the overseas Chinese, Chinese students, and the opening of civil martial arts schools boxer and so can be called folk spread. It should be the official communication and non-governmental exchanges combined official dissemination easier for people or high-level athletes to accept, and non-governmental exchanges is to allow more people to understand the amount of accepted traditional martial arts. Therefore, a favorable combination of official and civil exactly two can complement each other, the greater the impact surface, allowing more people to understand and accept ongoing over traditional martial arts.

\section{Conclusions and Recommendations}

Traditional Martial Arts Kun lack of research, technical complexity, training and other means obsolete direct impact on the development and popularity of the traditional martial arts; publicity efforts to promote traditional martial arts is not enough, relatively few traditional martial arts tournament, all the traditional martial arts schools lack of communication, traditional martial arts too little investment in the economy and so restricts the popularization and development of traditional martial arts.

Strengthen the traditional martial art of finishing and explore, formed its own technology and Theoretical System. Carry forward the traditional martial arts, to go abroad. Strengthen efforts to promote traditional martial arts world, full use of Chinese in the revitalization of traditional Chinese martial arts Advantages and favorable conditions to promote the martial arts, traditional martial arts competitions held worldwide. Inheritance and innovation both in the traditional martial arts development process through innovative highlighting traditional characteristics, promote the development of traditional Chinese martial arts.

\section{References}

[1] Cai Zhonglin. Adult Education College of Hubei University, Vol. 1 (2004) No 53, p.77-79

[2] Wang Gang, Wang Tiexin. People's Sports, Vol. 12 (2005) No 27, p.190

[3] Wang Fengming. Beijing Sport University, Vol. 30 (2005) No 19, p.144-145

[4] Yu Zhijun. Chinese Renmin University, Vol. 29 (2006) No 27, p.21-23 
湖北省武汉市洪山区白沙洲张家湾街 19 号, 武昌工学院 体育课部潘春光 18062449623 